\title{
CD47 as a potential prognostic marker for oral leukoplakia and oral squamous cell carcinoma
}

\author{
XIAOJING YE $^{1}$, XIAOJUN WANG $^{1}$, RUI LU $^{1,2}$, JING ZHANG $^{1,2}$, XINMING CHEN $^{1,3}$ and GANG ZHOU ${ }^{1,2}$ \\ ${ }^{1}$ The State Key Laboratory Breeding Base of Basic Science of Stomatology (Hubei-MOST) and Key Laboratory of \\ Oral Biomedicine Ministry of Education; Departments of ${ }^{2}$ Oral Medicine and ${ }^{3}$ Oral Pathology, \\ School and Hospital of Stomatology, Wuhan University, Wuhan, Hubei 430079, P.R. China
}

Received February 18, 2016; Accepted March 3, 2017

DOI: $10.3892 / \mathrm{ol} .2018 .8520$

\begin{abstract}
Cluster of differentiation (CD)47, which acts as a negative indicator for phagocytic cells, is overexpressed on the surface of multiple human solid tumor cell types. Avoiding phagocytosis by CD47 is required for the progression of solid tumors. The present study investigated the expression of CD47 in oral leukoplakia (OLK) and oral squamous cell carcinoma (OSCC), and preliminarily explored the impact of CD47 on the proliferation of OSCC cells. A total of 56 tissue samples, including 36 cases of OLK, 10 cases of OSCC and 10 cases of normal oral mucosa (NOM) were selected to detect the expression of CD47 by immunohistochemistry. For subgroup analysis, OLK samples were divided into OLK with low-risk dysplasia (LR-OLK) and OLK with high-risk dysplasia (HR-OLK). The subcellular localization of CD47 was determined by immunofluorescence in three OSCC cell lines (Tca8113, SCC-9 and Cal-27). The effect of CD47 antibody on the proliferation of the Cal-27 cell line was analyzed using the Cell Counting kit-8 assay. CD47 expression in OLK and OSCC lesions was significantly higher than in NOM $(\mathrm{P}<0.05)$. Compared with LR-OLK, the expression of CD47 in HR-OLK and OSCC cells was upregulated $(\mathrm{P}=0.0327$ and $\mathrm{P}=0.0048$, respectively). CD47 was highly expressed in OSCC cell lines (Tca8113, Cal-27 and SCC-9) and weakly expressed in normal oral keratinocytes. The proliferation of Cal-27 cells was inhibited by CD47 antibody in a concentration and time-dependent manner. CD47 may be a reliable biomarker for predicting the progression of oral precancer and cancer, and it may serve as an important molecular target for designing a novel therapy for oral cancer.
\end{abstract}

Correspondence to: Professor Gang Zhou, Department of Oral Medicine, School and Hospital of Stomatology, Wuhan University, 237 Luoyu Road, Wuhan, Hubei 430079, P.R. China

E-mail: zhougang@whu.edu.cn

Key words: cluster of differentiation 47, oral leukoplakia, oral precancer, oral squamous cell carcinoma

\section{Introduction}

Oral squamous cell carcinoma (OSCC) is one of the most common types of cancer in the world $(1,2)$. It is characterized by a high rate of cervical lymph node metastasis and poor prognosis (3). The histopathological development between oral precancer and oral cancer may undergo stages of epithelial hyperplasia, dysplasia, early invasive and lymph node metastasis (4). Oral precancers, which may lead to OSCC transformation, are a group of disorders of varying etiologies with or without clinical and histomorphological alterations (5). Oral leukoplakia (OLK) represents the most common oral precancerous lesion, with $0.13-3.5 \%$ of cases undergoing malignant transformation (6). The prognosis for patients with OSCC remains poor in spite of advances in therapy (6). Early detection of oral cancer is one of the most efficient ways to reduce the high mortality rate of the disease (7). Thus, early diagnosis and treatment are required to improve the survival rate.

Cluster of differentiation (CD)47, which belongs to the immunoglobulin superfamily, is a ligand for the extracellular domain of signal regulatory protein $\alpha(\operatorname{SIRP} \alpha)(8)$. CD47 is ubiquitously expressed on the surface of the majority of cell types, including $\mathrm{T}$ cells and epithelial cells (8). Functionally, CD47 acts as a marker of self for macrophages, and protects cells from phagocytosis (9). CD47-SIRP $\alpha$ engagement on macrophages leads to an inhibitory signal that negatively regulates activation and phagocytosis (10). In addition, through conjunction with integrins from the $\beta 1, \beta 2$ and $\beta 3$ families, CD47 initiates heterotrimeric G-protein signaling and thus modulates cell motility, leukocyte adhesion, migration and phagocytosis (8).

The interaction between CD47 and SIRP $\alpha$ is particularly important for the regulation of phagocytosis of malignant cells (9). Avoiding phagocytosis by infiltrated macrophages is required for the progression of solid tumors (9). Previous studies have reported that CD47 is overexpressed in cancer cells, and CD47 mRNA expression levels are associated with a decreased probability of survival for multiple types of cancer, including oophoroma and breast cancer $(11,12)$. Macrophages rely on CD47 expression to distinguish self from foreign and to set a threshold for macrophage-mediated phagocytosis of opsonized cells (9). CD47 binding to SIRP $\alpha$ may transduce 
inhibitory signals to decrease the phagocytic activity of macrophages and boost the immunological evasion of tumor cells, as well as tumor development (13). CD47-SIRP $\alpha$ interactions provide a rational basis for enhancing the effects of cancer therapy by antibody-mediated tumor cell elimination (14).

An interrupted interaction between CD47 and SIRP $\alpha$ has previously been reported to be beneficial for the treatment of malignant diseases, including human acute lymphoblastic leukemia, non-Hodgkin's lymphoma and bladder cancer, due to their function in promoting phagocytosis of tumor cells by macrophages (15-17). However, the expression and function of CD47 is not known in oral precancer and cancer. Thus, the present study investigated the expression of CD47 in the oral precancer and cancer, and preliminarily explored its impact on OSCC.

\section{Materials and methods}

Specimen collection. To detect the expression of CD47 in oral precancer and OSCC, 36 OLK and 10 OSCC specimens were selected from the Department of Oral Pathology, School and Hospital of Stomatology, Wuhan University (Wuhan, China). The present study was approved by the Ethics Committee of the Hospital of Stomatology, Wuhan University, and written informed consent was obtained from all patients. A total of 10 normal oral mucosal (NOM) samples (obtained during third molar removal) were used as the control. Clinicopathological parameters, including age, sex, lesion site and histological grade of dysplasia were obtained from pathological reports. For subgroup analysis, OLK samples were divided into OLK with low-risk dysplasia (LR-OLK) and OLK with high-risk dysplasia (HR-OLK), according to histological grading of OLK lesions in the scheme of the World Health Organization (2005) (18). LR-OLK was termed as OLK with hyperplasia or mild dysplasia, while HR-OLK was termed as OLK with moderate or severe dysplasia.

Immunohistochemistry. Tissue sections ( $4 \mu \mathrm{m})$ were deparaffinized in xylene and hydrated in a graded series of alcohols (30, 50, 70, 50, 90, 95 and 100\%). Antigen retrieval was performed using a $0.01 \mathrm{M}$ citric acid buffer solution ( $\mathrm{pH}$ 6.0) at high pressure for $90 \mathrm{sec}$. To block endogenous peroxidase activity, $3 \%$ hydrogen superoxide was applied at room temperature for $20 \mathrm{~min}$. Non-specific binding sites were blocked by incubation in 5\% normal goat serum (Zhongshan Golden Bridge Ltd., Beijing, China) for $30 \mathrm{~min}$ at $37^{\circ} \mathrm{C}$. The sections were then incubated at $4^{\circ} \mathrm{C}$ overnight in a diluted solution (dilution, 1:200) of monoclonal mouse anti-human CD47 (cat. no. MAB4670; R\&D Systems, Inc., Minneapolis, MN, USA). Sections were exposed to a second biotinylated goat anti-mouse immunoglobulin G antibody (cat. no. SAP9001; Zhongshan Golden Bridge Ltd.; 1:800) solution for $20 \mathrm{~min}$ at $37^{\circ} \mathrm{C}$. Following washing the sections with PBS $(0.01 \mathrm{M}$; $\mathrm{pH}=7.2$ ), staining was completed by incubation with 3'3-diaminobenzidine tetrachloride for $3 \mathrm{~min}$. The specimens were then counterstained with Mayer's hematoxylin, dehydrated using a graded series of ethanol (100, 95, 90, 70, 50 and 30\%), and mounted with a glass coverslip and xylene-based mountant. Negative controls were incubated with PBS instead of primary antibodies.
Immunohistochemical scoring. Images of each immunohistological section were captured for 5 randomly selected fields in the central areas, using light microscopy (magnification, x200 and x50; Olympus Corporation, Tokyo, Japan). Two independent oral pathologists (Department od Oral Medicine, School and Hospital of Stomatology, Wuhan University, Wuhan, China) blind to the clinical information of each patient interpreted the immunohistochemical results.

The cell cytoplasm and membrane localization of CD47 was categorized as positive expression, and the degree was calculated based on the percentage of positive cells and the staining intensity. The percentage of positive cells was scored as follows: $1, \leq 1 \%$ positive cells; $2,2-10 \%$ positive cells; $3,11-50 \%$ positive cells; and $4,>50 \%$ positive cells. The staining intensity of expression was rated as: 0 , negative; 1 , weak positive; 2 , moderate positive; and 3 , strong positive. Points for staining the intensity of expression and the percentage of positive cells were multiplied and the final score was dependent on the average score of 5 random fields of view.

Cell culture and immunofluorescence. Human oral keratinocytes (gifted by Professor Zhou Hongmei, Si Chuan University) were cultured in keratinocyte serum-free medium (Gibco; Thermo Fisher Scientific, Inc., Waltham, MA, USA) supplemented with $100 \mathrm{IU}$ penicillin and $100 \mu \mathrm{g} / \mathrm{ml}$ streptomycin at $37^{\circ} \mathrm{C}$ and $5 \% \mathrm{CO}_{2}$ in a humidified atmosphere. The oral cancer cells Tca8113, SCC-9 and Cal-27 (Type Culture Collection of the Chinese Academy of Sciences, Shanghai, China) were incubated in Dulbecco's modified Eagle's medium (DMEM) F-12, whilst Tea8113 and Cal-27 cells were cultured in DMEM supplemented with $10 \%$ fetal bovine serum (HyClone; GE Healthcare Life Sciences, Logan, UT, USA), penicillin $(100 \mathrm{U} / \mathrm{ml})$ and streptomycin sulfate $(100 \mu \mathrm{g} / \mathrm{ml})$, at $37^{\circ} \mathrm{C}$ under a humidified atmosphere of $5 \% \mathrm{CO}_{2}$.

For immunofluorescence, $2 \times 10^{4}$ cells were plated on cover slips and grown for $48 \mathrm{~h}$. Cells were fixed in $4 \%$ formaldehyde and permeabilized with PBS buffer. Subsequently, fixed cells were incubated with 5\% normal goat serum (Zhongshan Golden Bridge Ltd.) for $30 \mathrm{~min}$ at $37^{\circ} \mathrm{C}$ and mouse CD47 antibody (1:100; cat. no. FAB4670G; R\&D Systems, Inc.) was added overnight at $4^{\circ} \mathrm{C}$. Following three washes with ice-cold sterile PBS, the cells were incubated with Alexa Fluor 488 goat anti-mouse immunoglobulin G (1:100; cat. no. ZF-0512; Zhongshan Golden Bridge Ltd.) for $2 \mathrm{~h}$ at $37^{\circ} \mathrm{C}$. Nuclei were counterstained with DAPI, followed by observation under a fluorescence microscope (Leica Microsystems, Inc., Buffalo Grove, IL, USA; magnification, x200) with 5 fields of view assessed.

Cell proliferation assay. Cal-27 cells were seeded at a density of $2 \times 10^{3}$ cells per well on 96-well culture plates. Cal-27 cells were incubated with CD47 antibody (cat. no. MAB4670; R\&D Systems, Inc.) at $37^{\circ} \mathrm{C}$ at concentrations of 0,5 and $10 \mu \mathrm{g} / \mathrm{ml}$ for 48,72 and $96 \mathrm{~h}$, respectively. The relative cell number was then detected by the Cell Counting kit-8 (CCK-8) assay (Dojindo Molecular Technologies, Inc., Kumamoto, Japan), according to the manufacturer's protocol. CCK-8 solution (10 $\mu \mathrm{l}$ ) was added to each well during the last $2 \mathrm{~h}$ of culture at $37^{\circ} \mathrm{C}$, and the absorbance in each well was measured at 

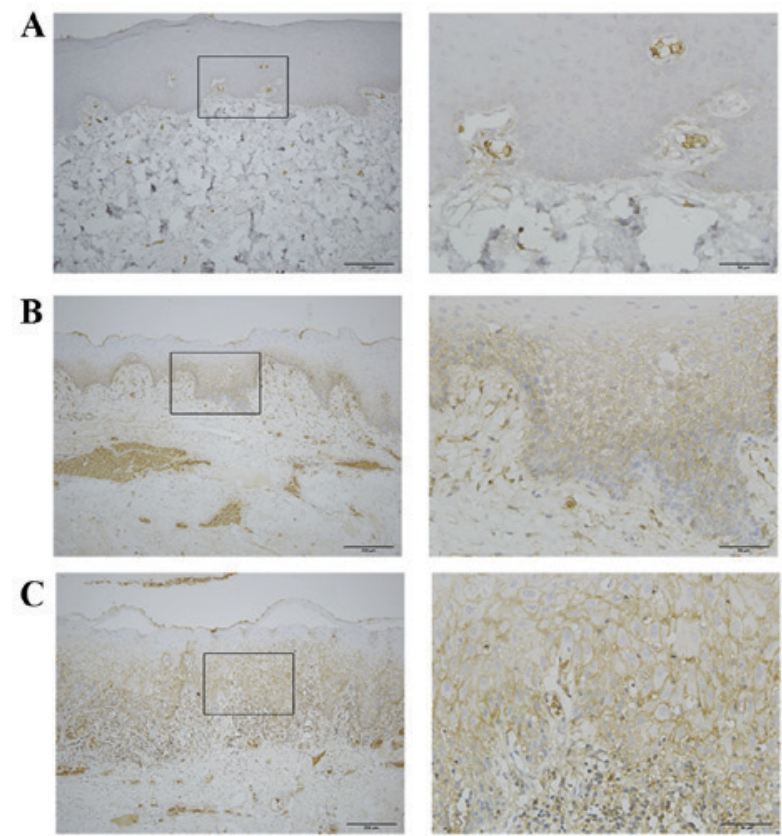

D

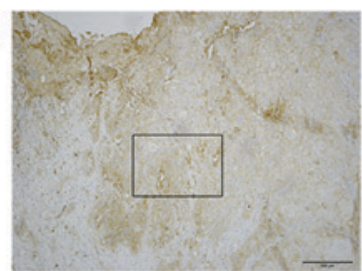

$\mathbf{E}$

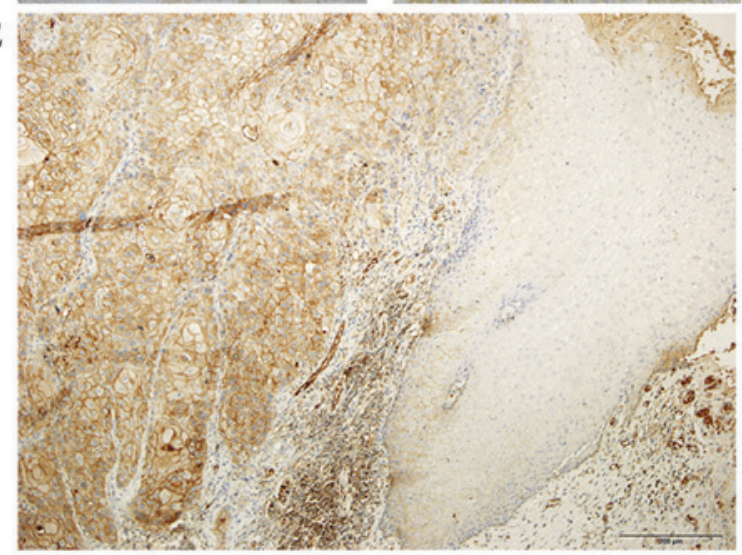

Figure 1. Expression of cluster of differentiation 47 in representative specimens. (A) Normal oral mucosa, (B) oral leukoplakia with low risk dysplasia (C) oral leukoplakia with high risk dysplasia, (D) oral squamous cell carcinoma (magnification, $x 100$ left, $x 400$ right). (E) A representative specimen that included normal oral mucosa (negative staining) and oral squamous cell carcinoma (strong positive staining).

$450 \mathrm{~nm}$ using a 96-well multiscanner autoreader (Thermo Fisher Scientific, Inc.).

Statistical analysis. Data were presented as the mean \pm standard error of the mean. Statistical analysis was performed using the GraphPad Prism 5 statistical package (GraphPad Software, Inc., La Jolla, CA, USA). The association between CD47 expression and histopathological levels was analyzed using the $\chi^{2}$ test. One-way analysis of variance was used to evaluate the differences between experimental and control groups, with Tukey's test used as a post-hoc test. $\mathrm{P}<0.05$ was considered to indicate a statistically significant difference.

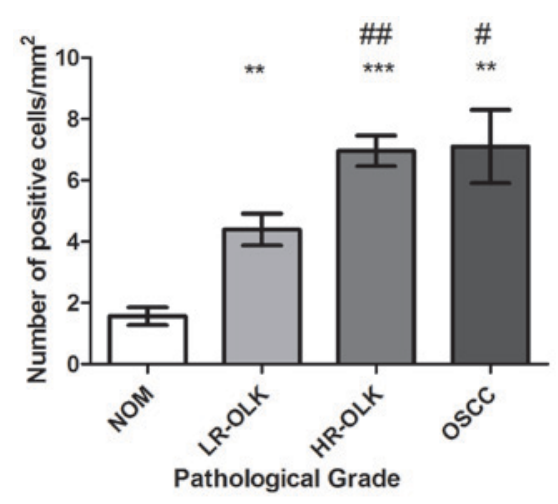

Figure 2. Comparison of expression of cluster of differentiation 47 in different groups. ${ }^{*} \mathrm{P}<0.05,{ }^{* *} \mathrm{P}<0.01$ and ${ }^{* * * *} \mathrm{P}<0.001$ vs. NOM group; ${ }^{*} \mathrm{P}<0.05$ and ${ }^{\# \#} \mathrm{P}<0.01$ vs. LR-OLK group. NOM, normal oral mucosa; LR-OLK, oral leukoplakia with low-risk dysplasia; HR-OLK, oral leukoplakia with high-risk dysplasia; OSCC, oral squamous cell carcinoma.

\section{Results}

Expression of CD47 in NOM, OLK and OSCC. The expression of CD47 was mainly localized on the cell membrane of epithelial cells, with little expression in the cytoplasm. There was very weak positive expression of CD47 in NOM (Fig. 1A). The expression of CD47 in the LR-OLK group was weak, primarily confined to the basal layer of the epithelium (Fig. 1B). In the HR-OLK group, strong staining was observed in the whole spinous layer (Fig. 1C). Almost all cell membrane of epithelial cells were positive for the expression of CD47 in OSCC (Fig. 1D). A prominent feature was that CD47 expression was positively stained in a region that exhibited dysplasia, but there was no expression in epithelium with normal appearance (Fig. 1E).

The mean expression score of CD47 in NOM was $1.56 \pm 0.93$, and its expression was significantly lower compared with oral epithelial dysplasia $(5.67 \pm 2.50 ; \mathrm{P}<0.0001)$ and OSCC (7.10 $\pm 3.76 ; \mathrm{P}=0.0057)$. In addition, the expression of CD47 in the LR-OLK, HR-OLK and OSCC groups was increased compared with NOM $(\mathrm{P}=0.0018, \mathrm{P}<0.0001$ and $\mathrm{P}=0.0057$, respectively; Fig. 2). The expression of CD47 in the OSCC and HR-OLK groups was significantly higher than in the LR-OLK group ( $\mathrm{P}=0.0327$ and $\mathrm{P}=0.0048$, respectively; Fig. 2$)$. The expression of CD47 in the OSCC group was slightly higher than in the HR-OLK group, but no statistical significance was observed.

Expression of CD47 in OSCC cell lines. To study the subcellular localization of CD47 protein, the expression of CD47 was detected in Tca8113, SCC-9 and Cal-27 cell lines, and normal oral keratinocytes, by immunofluorescence. CD47 expression was observed on the cytomembrane and cytoplasm of these cancer cell lines (Fig. 3). CD47 expression was absent or weak in normal oral keratinocytes.

CD47 antibody inhibits the proliferation of Cal-27 cells. The effect of CD47 antibody on the proliferation of the Cal-27 cell line was utilized by the CCK- 8 assay. The proliferation of Cal-27 cells was significantly inhibited by incubation with 5 and $10 \mu \mathrm{g} / \mathrm{ml} \mathrm{CD} 47$ antibody compared with the control 
A1

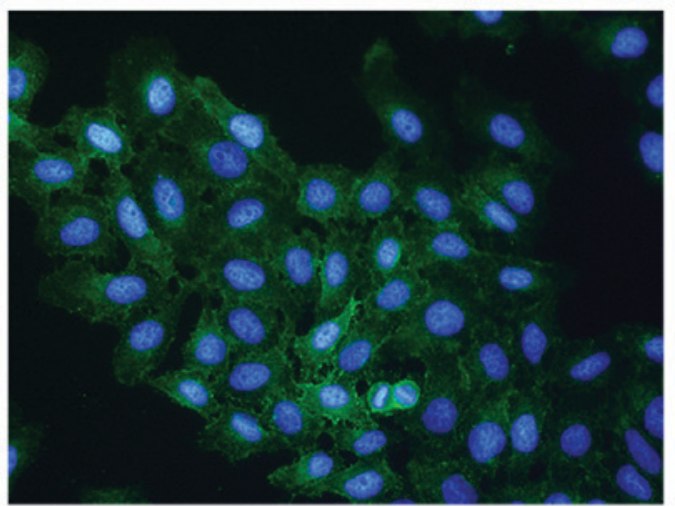

B1

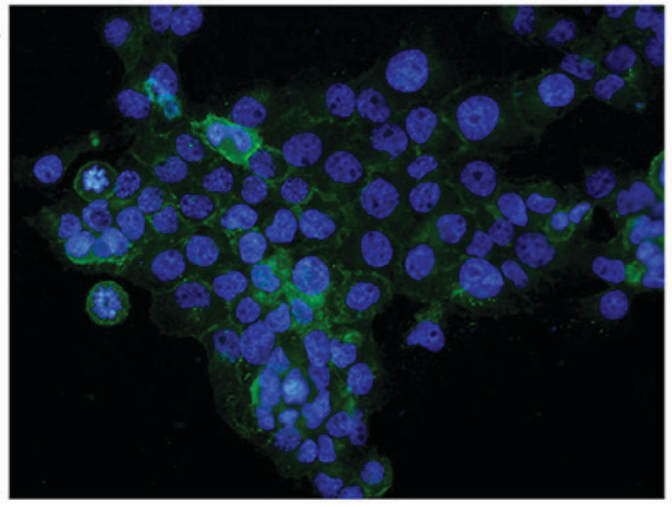

C1

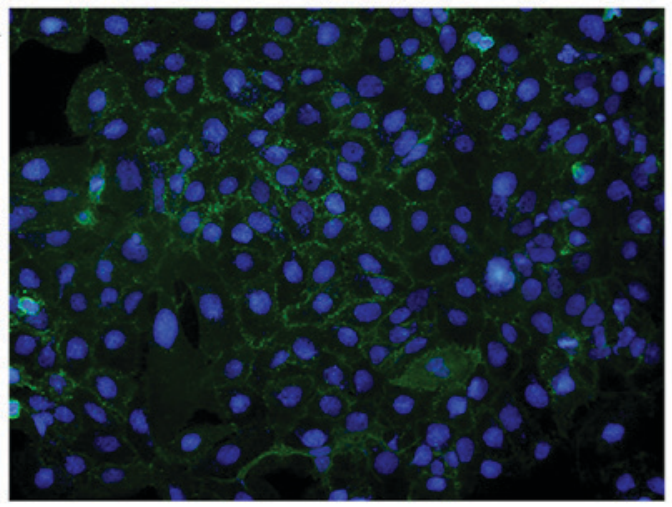

D1

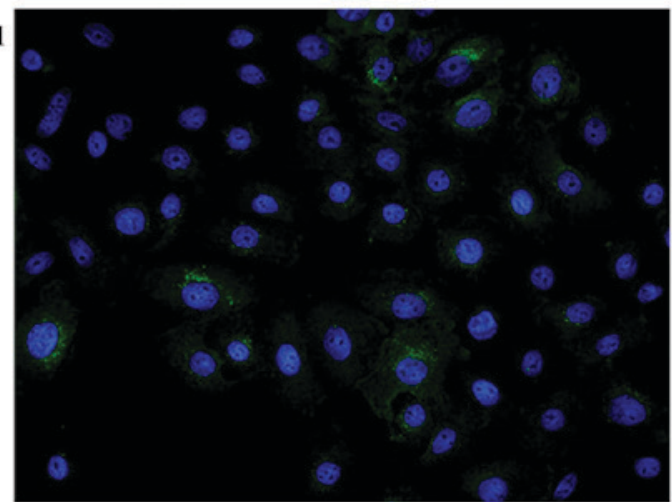

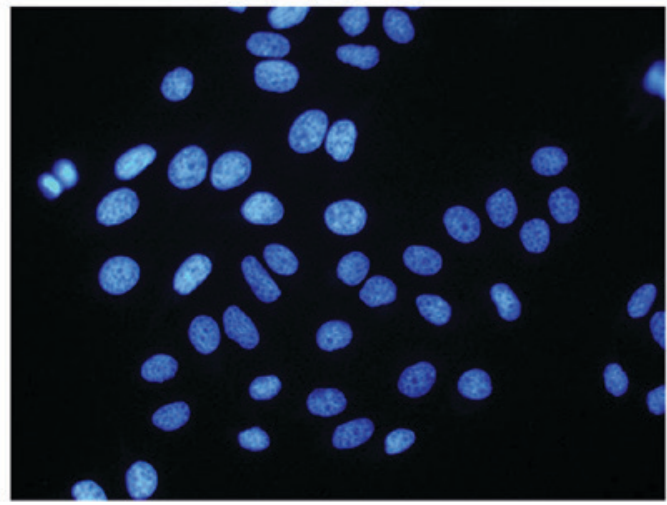

2

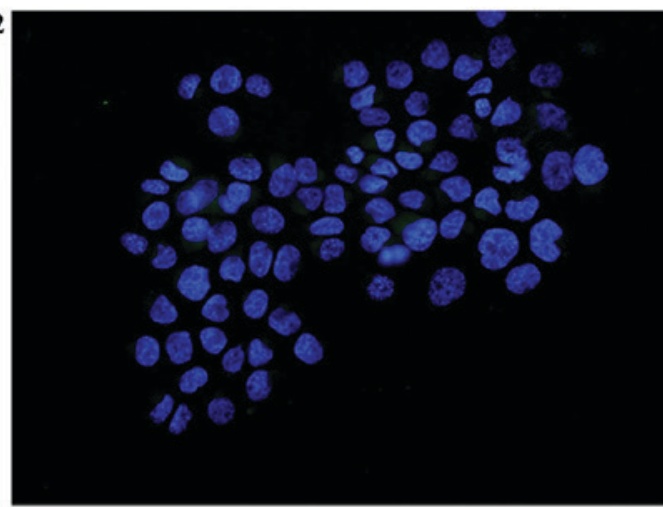

2

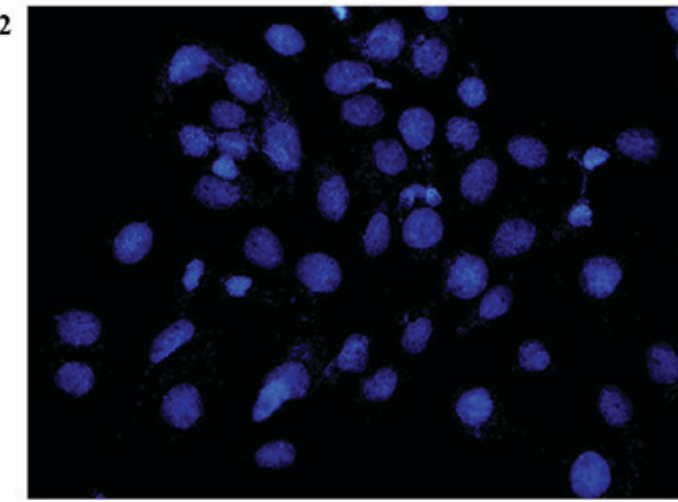

2

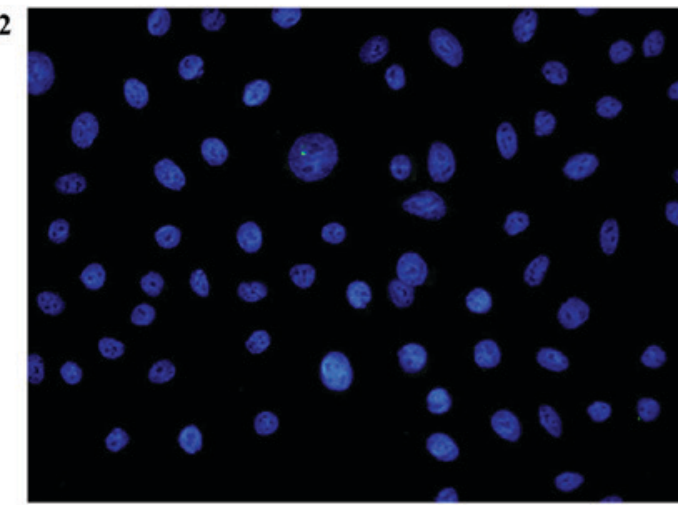

Figure 3. Expression of CD47 in oral squamous cell carcinoma cell lines and normal oral keratinocytes, as assessed by immunofluorescence. CD47 was expressed in (A1) Tca8113, (B1) Cal-27 and (C1) SCC-9 cells. (D1) Weak positive staining was observed in normal oral keratinocytes. No expression of CD47 was observed in the control cells (A2-D2; magnification, x400). CD47, cluster of differentiation 47.

group ( $\mathrm{P}<0.05$; Fig. 4). Following 72 and 96 h stimulation, the proliferation of Cal-27 cells was inhibited by incubation with $5 \mu \mathrm{g} / \mathrm{ml} \mathrm{CD} 47$ antibody, but no significant inhibition was observed following $48 \mathrm{~h}$ stimulation (Fig. 4). When the concentration of CD47 antibody was increased to $10 \mu \mathrm{g} / \mathrm{ml}$, significant inhibition appeared following 48, 72 and $96 \mathrm{~h}$ stimulation $(\mathrm{P}<0.05$; Fig. 4$)$, which manifested in a concentration- and time-dependent manner. 


\section{CCK-8}

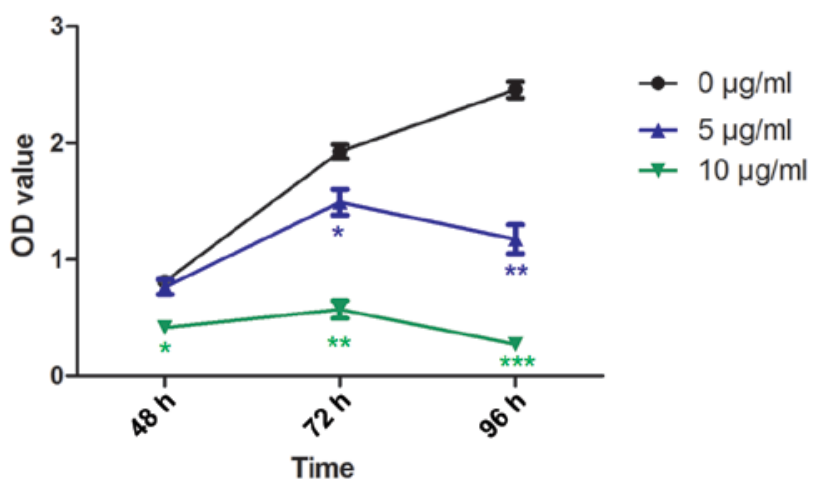

Figure 4. Effect of CD47 antibody on the proliferation of Cal-27 cells. The proliferation of Cal-27 cells was inhibited by 5 and $10 \mu \mathrm{g} / \mathrm{ml} \mathrm{CD} 47$ antibody. ${ }^{*} \mathrm{P}<0.05,{ }^{* *} \mathrm{P}<0.01$ and ${ }^{* * *} \mathrm{P}<0.001$ vs. control group. CD47, cluster of differentiation 47; OD, absorbance; CCK-8, Cell Counting kit-8.

\section{Discussion}

In the present study, the expression and function of CD47 was explored in oral precancer and cancer, and it was revealed that the expression of CD47 was increased in OLK and OSCC, and that CD47 antibody inhibited the proliferation of OSCC cells. CD47 may therefore serve as an important biomarker for the progression of oral precancer and cancer.

The expression of CD47 was previously reported to be upregulated in numerous types of cancer, including esophageal squamous cell carcinoma, colorectal cancer and colon cancer $(13,19)$. In addition, increased expression of CD47 has been demonstrated to contribute to pathogenesis by inhibiting phagocytosis of these cancer cells $(12,17,20)$. Thus, consistent with CD47 being a negative indicator for phagocytosis, CD47 on cancer cells acts to inhibit macrophage phagocytosis (21). Majeti et al (20) proposed that tumor cells evade macrophage phagocytosis and the killing effects of the innate immune system by upregulating the expression of CD47, therefore promoting tumorigenesis and metastasis. Edris et al (22) revealed that interference with CD47 increased phagocytosis of cancer cell lines and that treatment with CD47 antibody markedly inhibited the growth of xenotransplanted tumors. The present study revealed that CD47 was highly expressed on OLK and OSCC. OLK and OSCC may evade macrophage phagocytosis by upregulating the expression of CD47.

High expression levels of CD47 were associated with lymph node metastasis, which demonstrated that CD47 expression was an independent prognostic factor (12). In addition, increased CD47 mRNA expression levels in certain solid tumors were associated with a decreased probability of patient survival time (11). Thus, these results have created a rational basis for targeting CD47 as a biomarker in predicting cancer. OLK, as a potentially malignant oral disorder, may develop into OSCC graded between low risk and high risk dysplasia (23). The more severe the dysplasia, the greater the likelihood is of progression to malignancy (18). The results of the present study revealed that CD47 was mainly identified in OSCC, and that expression of CD47 was increased gradually between LR-OLK, HR-OLK and OSCC. This indicated that
CD47 may be a reliable biomarker for predicting the progression of oral precancer and cancer.

Engagement of SIRP $\alpha$ by CD47 provides a signal that inhibits host cell phagocytosis, and CD47 functions negative regulator of phagocytosis (8). In solid tumors, CD47 antibodies have been demonstrated to inhibit the proliferation of human head and neck squamous cell carcinoma cell lines, as well as primary human bladder cancers in vitro $(17,24)$. Phagocytosis of malignant cells increased when CD47 was blocked and CD47 antibody therapy inhibited tumor growth and prevented metastasis $(11,16)$. Treatment of tumor-bearing mice with antibodies that block CD47 signaling has produced tumor regression when used alone or combined with existing therapeutics $(13,14,25)$. Therapeutic monoclonal antibodies directed against tumor cells have become a valuable alternative to conventional cancer treatment modalities (14). A previous study identified that antibody and native ligands that serve as CD47 agonists may induce the death of breast cancer cells (14). Therefore, the effect of CD47 antibody on the proliferation of oral cancer cells was analyzed, and it was revealed that $\mathrm{CD} 47$ antibody inhibited the proliferation of Cal-27 cells. The overexpression of CD47 in OSCC by bonding with its ligand, SIRP $\alpha$, was speculated to reduce the phagocytosis function of macrophage and promote OSCC occurrence. Thus, CD47 may be a useful therapeutic target for oral cancer.

A previous study revealed that human solid tumor cells require CD47 expression to suppress phagocytic immune surveillance and elimination (9). Furthermore, evidence from several studies with different models suggested that CD47-SIRP $\alpha$ interactions were required for the induction of $\mathrm{T}$ cell-mediated autoimmunity, including Crohn's disease and colitis $(26,27)$. Soto-Pantoja et al (28) reported that blocking CD47 in the context of radiotherapy enhanced antitumor immunity by directly stimulating $\mathrm{CD} 8^{+}$cytotoxic $\mathrm{T}$ cells, with the potential to increase curative responses. Previous mechanistic studies indicated that CD47-SIRP $\alpha$ interactions are required for dendritic cell functions, in particular migration and/or antigen presentation, which are necessary to generate autoreactive T helper (Th)1 and/or Th17 cells $(26,29,30)$. OLK possesses the potential to transform into OSCC (31). T cells have been demonstrated to be associated with development and prognosis in OLK and OSCC (32). In addition, dendritic cells are present in the skin and mucosal linings, providing immunosurveillance to these tissue compartments (33). In accordance with the present study, CD47 is widely considered to serve an important function in $\mathrm{T}$ cell and dendritic cell-mediated immunosurveillance against cancer cells, indicating a potential mechanism of immune escape in OLK and oral cancer.

To conclude, CD47 may be a reliable biomarker for predicting the progression of oral precancer and cancer, and may serve as an important molecular target for designing novel therapies for oral cancer. Additional studies may elucidate the potential mechanism of CD47 as a therapeutic target of oral cancer.

\section{Acknowledgements}

The present study was supported by grants from the National Natural Science Foundation of China (grant nos. 81371147 and 81771080). 


\section{References}

1. Logan RM: 1st World Congress of the International academy of oral oncology: Oral cancer-a global challenge. Expert Rey Anticancer Ther 7: 975-976, 2007.

2. Kulkarni P and Saxena U: Head and neck cancers, the neglected malignancies: Present and future treatment strategies. Expert Opin Ther Targets 18: 351-354, 2014.

3. Quan J, Johnson NW, Zhou G, Parsons PG, Boyle GM and Gao J: Potential molecular targets for inhibiting bone invasion by oral squamous cell carcinoma: A review of mechanisms. Cancer Metastasis Rev 31: 209-219, 2012.

4. Warnakulasuriya S, Johnson NW and van der Waal I: Nomenclature and classification of potentially malignant disorders of the oral mucosa. J Oral Pathol Med 36: 575-580, 2007.

5. Sarode SC, Sarode GS and Tupkari JV: Oral potentially malignant disorders: Precising the definition. Oral Oncol 48: 759-760, 2012.

6. van der Waal I: Potentially malignant disorders of the oral and oropharyngeal mucosa; present concepts of management. Oral Oncol 46: 423-425, 2010.

7. Mehrotra R and Gupta DK: Exciting new advances in oral cancer diagnosis: Avenues to early detection. Head Neck Oncol 3: 33 , 2011.

8. Barclay AN and Van den Berg TK: The interaction between signal regulatory protein alpha (SIRP $\alpha)$ and CD47: Structure, function, and therapeutic target. Annu Rev Immunol 32: 25-50, 2014.

9. Jaiswal S, Chao MP, Majeti R and Weissman IL: Macrophages as mediators of tumor immunosurveillance. Trends Immunol 31: 212-219, 2010

10. Takizawa $\mathrm{H}$ and Manz MG: Macrophage tolerance: CD47-SIRP-alpha-mediated signals matter. Nat Immunol 8 : $1287-1289,2007$

11. Willingham SB, Volkmer JP, Gentles AJ, Sahoo D, Dalerba P, Mitra SS, Wang J, Contreras-Trujillo H, Martin R, Cohen JD, et al The CD47-signal regulatory protein alpha (SIRPa) interaction is a therapeutic target for human solid tumors. Proc Natl Acad Sci USA 109: 6662-6667, 2012

12. Suzuki S, Yokobori T, Tanaka N, Sakai M, Sano A, Inose T, Sohda M, Nakajima M, Miyazaki T, Kato $\mathrm{H}$ and Kuwano $\mathrm{H}$ : CD47 expression regulated by the miR-133a tumor suppressor is a novel prognostic marker in esophageal squamous cell carcinoma. Oncol Rep 28: 465-472, 2012.

13. Chao MP, Weissman IL and Majeti R: The CD47-SIRP $\alpha$ pathway in cancer immune evasion and potential therapeutic implications. Curr Opin Immunol 24: 225-232, 2012.

14. Zhao XW, van Beek EM, Schornagel K, Van der Maaden H, Van Houdt M, Otten MA, Finetti P, Van Egmond M, Matozaki T, Kraal G, et al: CD47-signal regulatory protein- $\alpha$ (SIRP $\alpha)$ interactions form a barrier for antibody-mediated tumor cell destruction. Proc Natl Acad Sci USA 108: 18342-18347, 2011.

15. Chao MP, Alizadeh AA, Tang C, Jan M, Weissman-Tsukamoto R, Zhao F, Park CY, Weissman IL and Majeti R: Therapeutic antibody targeting of CD47 eliminates human acute lymphoblastic leukemia. Cancer Res 71: 1374-1384, 2011.

16. Chao MP, Alizadeh AA, Tang C, Myklebust JH, Varghese B, Gill S, Jan M, Cha AC, Chan CK, Tan BT, et al: Anti-CD47 antibody synergizes with rituximab to promote phagocytosis and eradicate non-Hodgkin lymphoma. Cell 142: 699-713, 2010.

17. Chan KS, Espinosa I, Chao M, Wong D, Ailles L, Diehn M, Gill H, Presti J Jr, Chang HY, van de Rijn M, et al: Identification, molecular characterization, clinical prognosis, and therapeutic targeting of human bladder tumor-initiating cells. Proc Natl Acad Sci USA 106: 14016-14021, 2009.
18. Warnakulasuriya S, Reibel J, Bouquot J and Dabelsteen E: Oral epithelial dysplasia classification systems: Predictive value, utility, weaknesses and scope for improvement. J Oral Pathol Med 37: 127-133, 2008.

19. Lascorz J, Bevier M, V Schönfels W, Kalthoff H, Aselmann H, Beckmann J, Egberts J, Buch S, Becker T, Schreiber S, et al: Association study identifying polymorphisms in CD47 and other extracellular matrix pathway genes as putative prognostic markers for colorectal cancer. Int J Colorectal Dis 28: 173-181, 2013.

20. Majeti R, Chao MP, Alizadeh AA, Pang WW, Jaiswal S, Gibbs KD Jr, van Rooijen N and Weissman IL: CD47 is an adverse prognostic factor and therapeutic antibody target on human acute myeloid leukemia stem cells. Cell 138: 286-299, 2009.

21. Jaiswal S, Jamieson CH, Pang WW, Park CY, Chao MP, Majeti R, Traver D, van Rooijen N and Weissman IL: CD47 is upregulated on circulating hematopoietic stem cells and leukemia cells to avoid phagocytosis. Cell 138: 271-285, 2009.

22. Edris B, Weiskopf K, Volkmer AK, Volkmer JP, Willingham SB, Contreras-Trujillo H, Liu J, Majeti R, West RB, Fletcher JA, et al: Antibody therapy targeting the CD47 protein is effective in a model of aggressive metastatic leiomyosarcoma. Proc Natl Acad Sci USA 109: 6656-6661, 2012.

23. Zhu G, He Y, Yang S, Chen B, Zhou M and Xu XJ: Identification of Gene and MicroRNA signatures for oral cancer developed from oral leukoplakia. Biomed Res Int 2015: 841956, 2015.

24. Kim MJ, Lee JC, Lee JJ, Kim S, Lee SG, Park SW, Sung MW and Heo DS: Association of CD47 with natural killer cell-mediated cytotoxicity of head-and-neck squamous cell carcinoma lines. Tumour Biol 29: 28-34, 2008.

25. Chao MP, Tang C, Pachynski RK, Chin R, Majeti R and Weissman IL: Extranodal dissemination of non-Hodgkin lymphoma requires CD47 and is inhibited by anti-CD47 antibody therapy. Blood 118: 4890-4901, 2011.

26. Fortin G, Raymond M, Van VQ, Rubio M, Gautier P, Sarfati M and Franchimont D: A role for CD47 in the development of experimental colitis mediated by SIRPalpha+CD103-dendritic cells. J Exp Med 206: 1995-2011, 2009.

27. Baba N, Van VQ, Wakahara K, Rubio M, Fortin G, Panzini B, Soucy G, Wassef R, Richard C, Tamaz R, et al: CD47 fusion protein targets CD172a+ cells in Crohn's disease and dampens the production of IL-1beta and TNF. J Exp Med 210: 1251-1263, 2013.

28. Soto-Pantoja DR, Terabe M, Ghosh A, Ridnour LA, DeGraff WG, Wink DA, Berzofsky JA and Roberts DD: CD47 in the tumor microenvironment limits cooperation between antitumor T-cell immunity and radiotherapy. Cancer Res 74: 6771-6783, 2014.

29. Bian Z, Guo Y, Ha B, Zen K and Liu Y: Regulation of the inflammatory response: Enhancing neutrophil infiltration under chronic inflammatory conditions. J Immunol 188: 844-853, 2012.

30. Tomizawa T, Kaneko Y, Kaneko Y, Saito Y, Ohnishi H, Okajo J, Okuzawa C, Ishikawa-Sekigami T, Murata Y, Okazawa H, et al: Resistance to experimental autoimmune encephalomyelitis and impaired $\mathrm{T}$ cell priming by dendritic cells in Src homology 2 domain-containing protein tyrosine phosphatase substrate-1 mutant mice. J Immunol 179: 869-877, 2007.

31. Anderson A and Ishak N: Marked variation in malignant transformation rates of oral leukoplakia. Evid Based Dent 16: 102-103, 2015.

32. Öhman J, Mowjood R, Larsson L, Kovacs A, Magnusson B, Kjeller G, Jontell M and Hasseus B: Presence of CD3-positive T-cells in oral premalignant leukoplakia indicates prevention of cancer transformation. Anticancer Res 35: 311-317, 2015.

33. Murata Y,Kotani T, Ohnishi H and Matozaki T: The CD47-SIRPo signalling system: Its physiological roles and therapeutic application. J Biochem 155: 335-344, 2014.

This work is licensed under a Creative Commons Attribution-NonCommercial-NoDerivatives 4.0 International (CC BY-NC-ND 4.0) License. 